\title{
Patent Strategy and Layout Instrument--Derivative Design Patents
}

\author{
Rain Chen ${ }^{1} \&$ Hsin-Yu Chang ${ }^{2}$ \\ ${ }^{1}$ Department of Creative Product Design, Southern Taiwan University of Science and Technology, Tainan, Taiwan \\ ${ }^{2}$ Graduate Institute of Digital Content and Animation Design, Southern Taiwan University of Science and \\ Technology, Tainan, Taiwan \\ Correspondence: Dr. Rain Chen, Department of Creative Product Design, Southern Taiwan University of Science \\ and Technology, No. 1, Nan-Tai Street, Yongkang Dist., Tainan City 710, Taiwan. E-mail: ocean@mail.stust.edu.tw
}

Received: June 3, 2014

Accepted: June 29, 2014

Online Published: August 10, 2014

doi:10.5430/jms.v5n3p35

URL: http://dx.doi.org/10.5430/jms.v5n3p35

\begin{abstract}
As product technology matures, consumers will shift the focus onto the appearance and design of products. In recent years, the fierce competition between Apple and Samsung in the consumer electronics market has pushed the design patent domain into the spotlight. In Taiwan, the amendment of Taiwan Patent Act in 2011 has the Associated Design Patent (ADP) system replaced by the Derivative Design Patent (DDP) system. This is definitely a major patent reform. The DDP system is similar to the continuation application system of the US. In this study, a total of 40 Patent Professionals (PP) and Design Professionals (DP) participated in the study. The investigators also constructed a substantive DDP scope. The study results are presented below. The DDP system provides designers with a broader scope of patent rights, and this positive result would encourage companies to value design patent layouts. Overall, the DDP system provides more comprehensive design protection compared to the previous one, which is beneficial for Taiwan's heading into the creative sectors. For patent strategy per se, the DDP system makes design patent rights more solidly rooted. Companies in the future should make a good use of DDP for patent layouts. By doing so, the original design patents can be well protected from imitation or plagiarism. For design strategies, greater differences between DDPs would maximize the created patent scope. The conclusion here can be used as a new instrument by industries in planning their patent layouts.
\end{abstract}

Keywords: design patent, derivative design patent (DDP), associated design patent (ADP), patent professionals (PP), design professionals (DP), patent strategy, patent scope

\section{Introduction}

Intellectual property right is a knowledge-based economic system driven by innovation and productivity (Zhang et al., 2007). Intellectual property rights are used as economic incentives by the state government, and granting companies intellectual property rights is like granting them the right to monopolize. Nevertheless, the standards vary among countries (Davis, 1993). During the development process of new products, companies often neglect the importance of correctly using intellectual property rights for protection (Morris, 2012). In recent years, large companies have started to put emphasis on design patent not only to protect their products from plagiarizations but also to make the products innovative, i.e., ensuring the characteristics of their products can be easily identified by consumers, by using design patents to protect the appearance of their products. The most important goal for companies to apply for design patents is to understand and to confirm the substantive scope of their claimed patents in order to prevent patent infringement. Through the use of patent analysis and applications to facilitate the process of product innovation, the outcomes and quality of the design as well as the ideas can be effectively improved (Qiu et al., 2011). Patent infringement is now a critical issue when developing new products, and evading competitors' patents is an ongoing problem challenging designers (Hsu et al., 2009).

In terms of innovation types, it could be divided into function innovation and form innovation. Function innovation usually uses inventions patent to protect the creations; form innovation usually uses design patents to protect the form and shape. The countries worldwide which set up the system of patents, the types of patent could be divided into 3 different types which are invention patent, utility model patents and design patent (Chen and Kuo, 2013).

To avoid the infringement of design patents falling into the subjective judgement from the judge, Intellectual Property Office (TIPO, 2014) announced a flowchart of patent infringement for examining. The six steps as follows: 
(1) To explain the claim of design patent; (2) To explain the content of the item which is waiting to identify; (3) To judge the design patent and the item which is waiting identify whether to be equal to another one, or similar to; (4) To judge the shape, pattern, color and the visual design of design patent of the item which is waiting to identify whether it is identically the same or similar to; (5) To judge the shape, pattern, color and the design traits of design patent of the item which is waiting to identify whether it is identically the same or similar to; (6) To judge the item which is waiting to identify whether the item is applicable to use the "Prosecution history estoppel" or "Prior art limitation".

Although the lifespan of design patents is shorter, it can suppress plagiarism while enhancing product protection effectively. Companies can use the patent scope analysis diagram for their patent layouts (Chen et al., 2011; Chen et al., 2011). The design patent scope analysis diagram is an important tool for formulating design strategies (Chen and Chen, 2007) and innovative decision making (Cao and Zhao, 2008).

Taiwan's design patent is originated from Design Act of Japan. According to Paragraph 2 of Article 2, the term design is used to describe creative works in which the shapes, patterns, colors, or the combination of articles are manipulated (or part of an article) to visually elicit aesthetic appreciation (Hwang, 2004).

In general, "resorting to vision" means making observation through the eyes. The term visual appeal in the industrial design protection system is about making discrimination based on visual impression generated from observing the appearance design with the eyes. In other words, appearance design produces a differentiating effect based on psychological and visual impression induced by observation (Yeh, 2010).

When developing new products, several similar designs would be created according to the same design concept. Already designed products can also be modified because of market changes. The above two are two derivative design patent (DDP) concepts. The creator can only apply one patent for one design. For two identical designs or designs with indiscrimminable patentability, the creator may apply for separate patent right, but if both of them are approved, double patenting happens. Therefore, the second patent application would normally be refused to prevent double patenting (Yeh, 2005). Under the DDP system, variations developed based on the same design concept can be protected by the original design patent. In other words, the original design patent and DDP share a patent scope that is concretely identical. Nonetheless, the application period for derivative design cases is shorter in the DDP system (Yeh, 2009).

Conceptually, the DDP system is similar to the continuation application system of the US and the DDP system can be a very good tool for design patent layouts. When an identical patent was improved and resubmitted for patent application, the updated version will be the DDP of the original design patent. DDP application cases should be submitted only after the original design patent application but before the date the approval is announced. For the term of patent rights, DDP should be expired as the original design patent expires.

Taiwan's Patent Act was amended in 2011, and the DDP system was implemented in 2013. In the amendment, the associated design patent (ADP) system was replaced by the DDP system. It is definitely a major patent reform. The study used actual design cases to analyze whether the patent right scope has been broadened after the ADP system was replaced by the DDP system in the new law.

\section{Method}

\subsection{Subjects}

The study wants to construct a concrete design patent scope and to compare patent professionals (PP) with design professionals (DP) in terms of their judgment on patent samples. The investigators were looking for concrete differences between the two types of professionals. Therefore, the test subjects were divided into two groups (20 PP and 20 DP) for the experiment. The subjects have to be professionals in the PP or DP domain and with more than three years of experience.

\subsection{Samples}

In order to illustrate a concrete scope of design patents, the investigator collected appropriate patent samples from the patent database of Taiwan. Because the DDP system was only implemented on January 1, 2013, not many DDP patent samples were available then for discussion, and thus in this study, lots of ADP samples were used as the patent samples. Lastly, the study selected patent application number 087305353 (patent name: Design patent for sockets) as the main study sample, and the patent owner is Amyl Chi Corporation. To differentiate between ADP and DDP in patent scope, the study used A1 to A11 for ADP, while D1 to D11 for DDP (A1 = D1, A2 = D2, and so forth). O1 denotes the original patent application case of ADP and DDP. Patent sample coding is presented in Table 1. Drawings of the selected patent samples are shown in Figure 1. 
Table 1. Patent sample coding and profiles

\begin{tabular}{lllllllll}
\hline $\begin{array}{l}\text { Coding } \\
\text { of ADP }\end{array}$ & $\begin{array}{l}\text { Coding } \\
\text { of DDP }\end{array}$ & Application No. & $\begin{array}{l}\text { Patents } \\
\text { Category }\end{array}$ & $\begin{array}{l}\text { Application } \\
\text { Date }\end{array}$ & $\begin{array}{l}\text { Publication } \\
\text { Date }\end{array}$ & $\begin{array}{l}\text { Patent } \\
\text { Term }\end{array}$ & Nationality & Sources \\
\hline O1 & O1 & 087305353 & $13 ; 46 / 121$ & $1998 / 07 / 23$ & $2000 / 07 / 11$ & $2004 / 7 / 11$ & TW & Bel, 2000 \\
\hline A1 & D1 & $087305353 \mathrm{U} 01$ & $13 ; 46 / 121$ & $1998 / 07 / 24$ & $2000 / 12 / 01$ & $2004 / 7 / 11$ & TW & Bel, 2000 \\
\hline A2 & D2 & $087305353 \mathrm{U} 02$ & $13 ; 46 / 121$ & $1998 / 07 / 24$ & $2000 / 12 / 01$ & $2004 / 7 / 11$ & TW & Bel, 2000 \\
\hline A3 & D3 & $087305353 \mathrm{U} 03$ & $13 ; 46 / 121$ & $1998 / 07 / 24$ & $2000 / 12 / 01$ & $2004 / 7 / 11$ & TW & Bel, 2000 \\
\hline A4 & D4 & $087305353 \mathrm{U} 04$ & $13 ; 46 / 121$ & $1998 / 07 / 24$ & $2000 / 12 / 01$ & $2004 / 7 / 11$ & TW & Bel, 2000 \\
\hline A5 & D5 & $087305353 \mathrm{U} 05$ & $13 ; 46 / 121$ & $1998 / 07 / 24$ & $2000 / 12 / 01$ & $2004 / 7 / 11$ & TW & Bel, 2000 \\
\hline A6 & D6 & $087305353 \mathrm{U} 06$ & $13 ; 46 / 121$ & $1998 / 07 / 24$ & $2000 / 12 / 01$ & $2004 / 7 / 11$ & TW & Bel, 2000 \\
\hline A7 & D7 & $087305353 \mathrm{U} 07$ & $13 ; 46 / 121$ & $1998 / 07 / 24$ & $2000 / 12 / 01$ & $2004 / 7 / 11$ & TW & Bel, 2000 \\
\hline A8 & D8 & $087305353 \mathrm{U} 08$ & $13 ; 46 / 121$ & $1998 / 07 / 24$ & $2000 / 12 / 01$ & $2004 / 7 / 11$ & TW & Bel, 2000 \\
\hline A9 & D9 & $087305353 \mathrm{U} 09$ & $13 ; 46 / 121$ & $1998 / 07 / 24$ & $2000 / 12 / 01$ & $2004 / 7 / 11$ & TW & Bel, 2000 \\
\hline A10 & D10 & $087305353 \mathrm{U} 010$ & $13 ; 46 / 121$ & $1998 / 07 / 24$ & $2000 / 12 / 01$ & $2004 / 7 / 11$ & TW & Bel, 2000 \\
\hline A11 & D11 & $087305353 \mathrm{U} 02$ & $13 ; 46 / 121$ & $1998 / 07 / 24$ & $2000 / 12 / 01$ & $2004 / 7 / 11$ & TW & Bel, 2000 \\
\hline
\end{tabular}
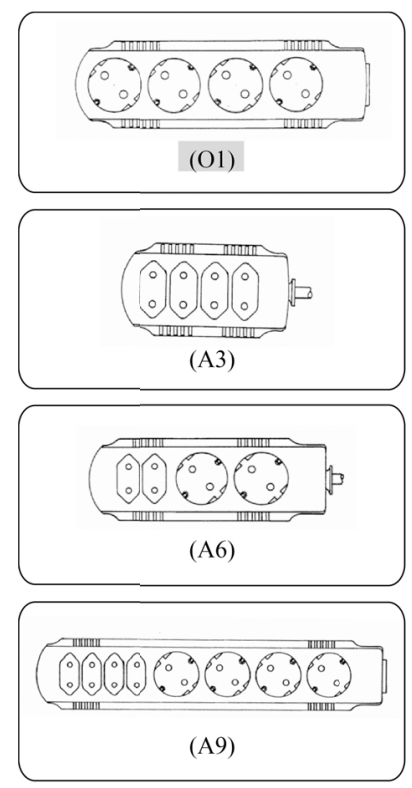
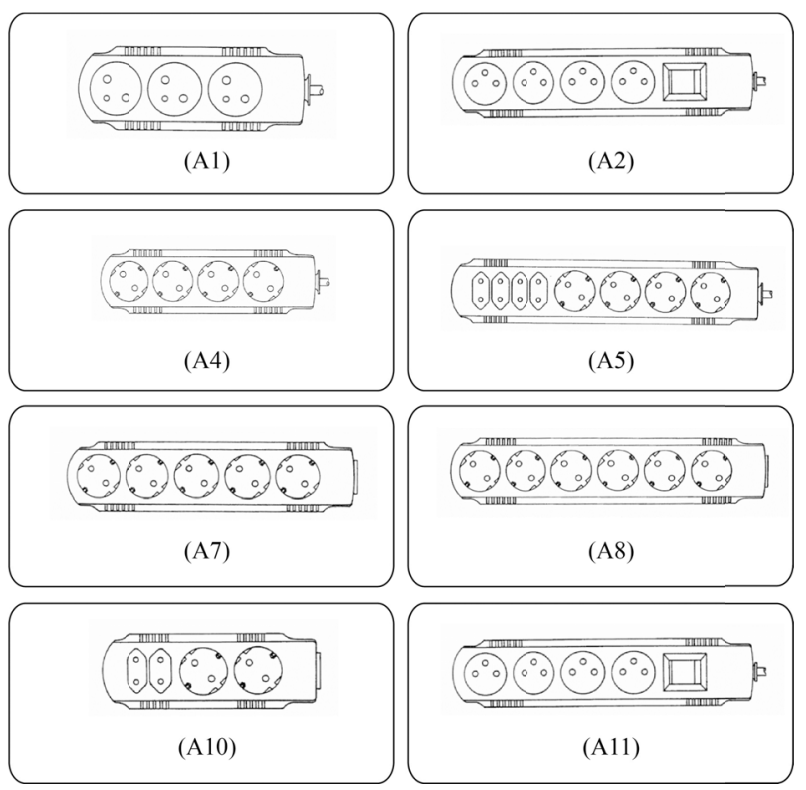

Figure 1. Patent sample drawings

\subsection{Experimental Design and Process}

The study first recruited PP and DP $(\mathrm{N}=20$ each) with more than three years of professional experience. These professionals were asked to arrange the products in Figure 1 according to the level of similarity of their appearance (placing those with a more similar look closer to each other). Afterward, the experimenters fixed the result and photographed it for measuring the distance.

To understand the scope of rights of actual DDP cases, the following experimental procedure was developed. In Step 1 , subjects were asked to put $\mathrm{O} 1$ at the center of the paper board and using $\mathrm{O} 1$ as the reference point. Then cards with the drawing of A1 to A11 were to be arranged in relation to the reference point. The subjects were asked to determine the level of similarity between O1 and A1 to A11. See Figure 2(a). In Step 2, subjects were asked to confirm the level of similarity between O1 and A1 to A11. See Figure 2(b). In Step 3, subjects were asked to slightly adjust A1 to A11, but during the adjustment, the distance between $\mathrm{O} 1$ and A1 to A11 should not be arbitrarily altered. See Figure 2(c). 


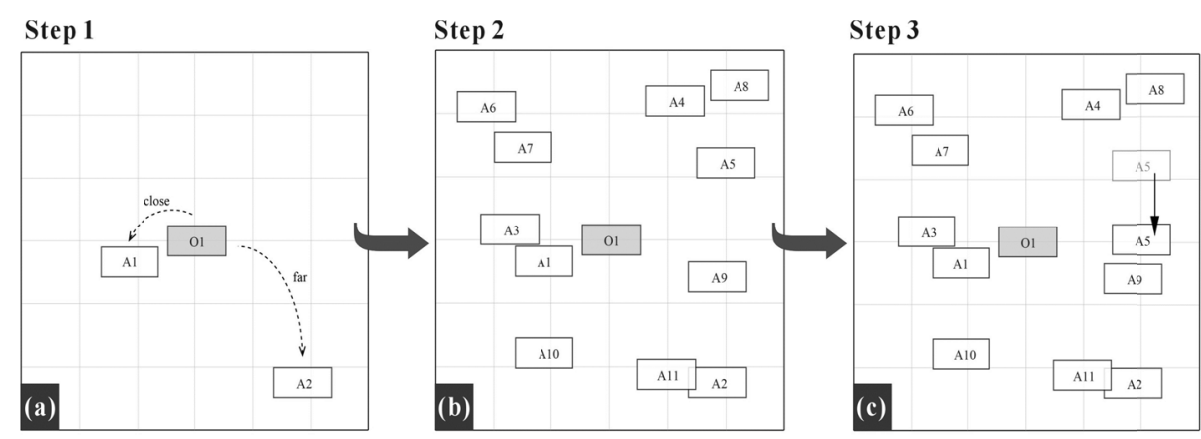

Figure 2. Experiment procedure

After completing the above-mentioned experiment procedure, the experimenters started to measure the physical distance between $\mathrm{O} 1$ an A1-A111. The collected data were analyzed using SPSS statistical software for multidimensional scaling analysis in which the numerical data were converted into the visualized design patent scope analysis diagram.

\section{Result}

\subsection{Basic Profile Analysis}

A total of 40 questionnaires were distributed to the subjects; twenty of them were filled out and returned by PP, and another twenty were filled out and returned by DP. All the returned questionnaires were valid. The basic profiles of the subjects are presented below.

(1) Gender

Most PP are male ( $\mathrm{N}=18 ; 90 \%)$, and only two PP are female (10\%). The difference in the number of male vs. female is significant.

For DP, there are 11 males (55\%) and 9 females (45\%). The number of male and of female are pretty even.

(2) Age

Most of the PP are between 26 and 30 years old $(\mathrm{N}=9 ; 45 \%)$, between 31 and 35 the second $(\mathrm{N}=6 ; 30 \%)$, between 21 and 25 the third $(\mathrm{N}=2 ; 10 \%)$ and between 36 and 40, between 46 and 50, and between 51 and 55 the fourth $(\mathrm{N}=$ $1 ; 5 \%)$. PP subjects are younger.

Most of the DP are between 21 and 25 years old $(\mathrm{N}=9 ; 45 \%)$, between 26 and 30 the second $(\mathrm{N}=5 ; 25 \%)$, between 31 and 35 the third $(\mathrm{N}=5 ; 25 \%)$ and between 41 and 45 the fourth $(\mathrm{N}=1 ; 5 \%)$. DP subjects are also younger.

(3) Current Job Domain

Most PP are patent attorneys and patent engineers $(\mathrm{N}=17 ; 85 \%)$. The remaining people are from other domains (such as patent services) $(\mathrm{N}=3 ; 15 \%)$.

Most DP are from the industrial design or cultural creative industries $(\mathrm{N}=13 ; 65 \%)$. The remaining people are from other domains, such as graphic design and photographing (35\%).

(4) Years of Professional Experience

For PP, 11 of them have 2 to 4 (including 4) years of professional experience (55\%), 6 of them 4 to 6 (including 6) years of experience (30\%), and 3 of them more than 10 years of experience (15\%). In average, PP in the study in average have more than 3 years of experience.

For DP, 13 of them have 2 to 4 (including 4) years of professional experience (65\%), 8 of them 6 to 8 (including 4) years of experience (20\%), and 3 of them 8 to 10 years of experience (15\%). In average, DP in the study have more than 3 years of experience.

(5) Level of Familiarity

For PP, 8 of them consider themselves slightly familiar with the study samples (40\%), 7 medium familiar (35\%), and 5 fully familiar $(25 \%)$.

For DP, 10 of them consider themselves slightly familiar with the study samples (50\%), 6 fully familiar (30\%), 2 medium familiar (10\%), and 2 not very familiar (10\%). 


\subsection{ADP Design Patent Scope}

There were $10 \mathrm{ADP}$ of $\mathrm{O} 1$ (coded as A1 to A10). To test subjects' validity, A11 was used as the check point in the experiment, and its contents were exactly identical with A2, and therefore, A11 was illustrated using dotted lines and its patent scope was not drawn. The date presented next to the patent sample code was the application date of the case. Because ADP lacks concrete and independent rights, the scope of rights of the original patent design (O1) was presented using dotted line. Any part exceeding the dotted line means that it is dissimilar to O1.

(1) Patent Professionals, PP

The ADP scope of presented by PP is shown in Figure 3. It can be found from Figure 3 that the scope of rights of the original design patent constructed by PP has an oval shape and the distance between O1 and each ADP is different (meaning different similarity levels). Specially, A6 and A9 are very similar, meaning that PP considered that the two designs have a very similar appearance.

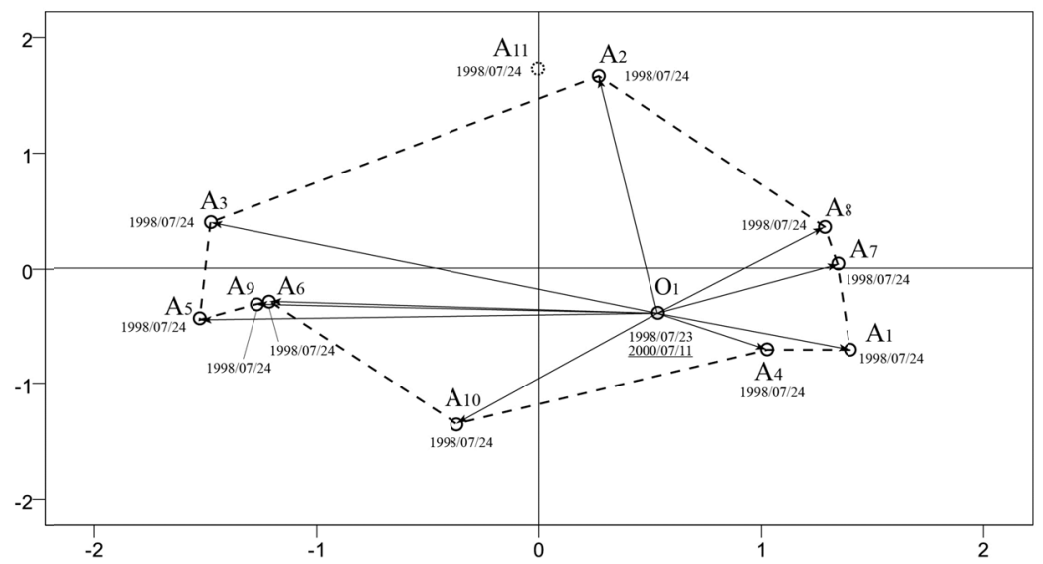

Figure 3. ADP scope constructed by patent professionals

(2) Design Professionals, DP

The ADP scope of presented by DP is shown in Figure 4. It can be found from Figure 4 that the scope of rights of the original design patent constructed by DP has irregular polygon and the distance between O1 and each ADP is different (meaning different similarity levels). Specially, A5 and A9 are very similar, meaning that DP considered that the two designs have a very similar appearance.

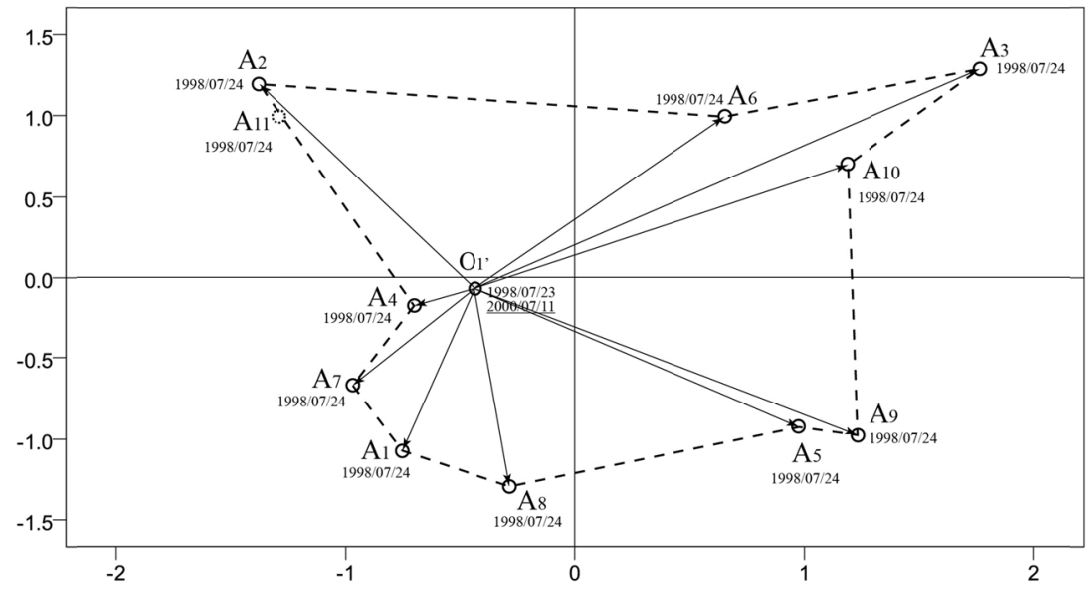

Figure 4. ADP scope constructed by design professionals 


\subsection{DDP Design Patent Scope}

There were 10 DDP of O1 (coded as D1 to D10). To test subjects' validity, D11 was used as the check point in the experiment, and its contents were exactly identical with D2, and therefore, D11 was illustrated using dotted lines and its patent scope was not drawn. The date presented next to the patent sample code was the application date of the case. Because DDP have concrete and independent rights, the scope of rights of the original patent design (O1) was presented using solid line. Although DDP has an independent patent scope, the size of the scope remains unclear. Therefore, each of the patent scope in DDP was presented using dotted circles.

(1) Patent Professionals, PP

The DDP scope of PP is shown in Figure 5. It can be found from Figure 5 that the scope of rights of the original design patent constructed by PP has the shape of an independent circle, and the scope of each DDP (D1-D10) also has the shape of an independent circle.

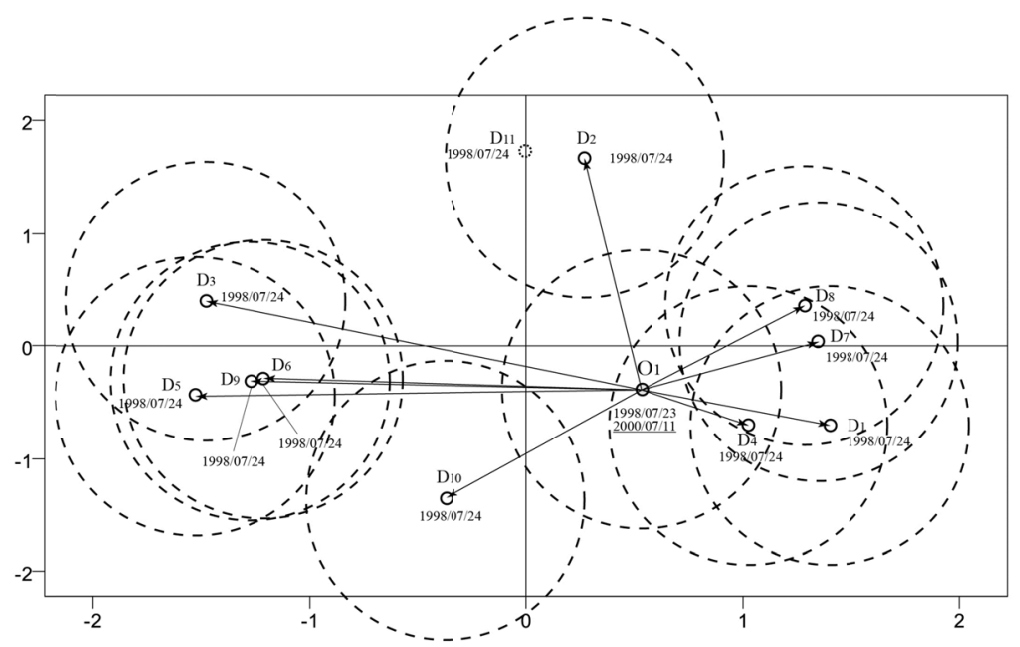

Figure 5. DDP scope constructed by patent professionals

(2) Design Professionals, DP

The DDP scope of DP is shown in Figure 6. It can be found from Figure 6 that the scope of rights of the original design patent constructed by DP has the shape of an independent circle, and the scope of each DDP (D1-D10) also has the shape of an independent circle.

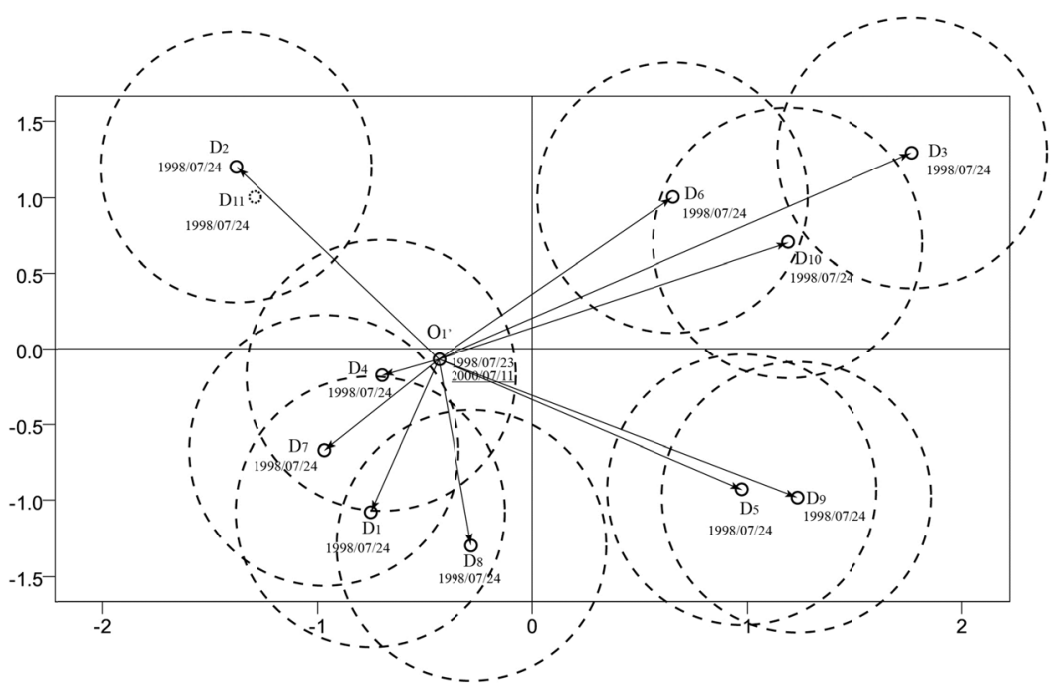

Figure 6. DDP scope constructed by design professionals 


\subsection{Differences in Design Patent Scope between ADP and DDP}

There were a total of $10 \mathrm{ADP}$ of O1 (coded as A1 to A10) and 10 DDP of O1 (coded as D1 to D10). Because ADP can exist only under O1, the relationships between O1 and A1-A10 were illustrated using solid lines. Although DDP has an independent patent scope, the size of the scope remains unclear. Therefore, each of the patent scope in DDP was presented using dotted circles.

(1) Patent Professionals, PP

Comparison of the coverage of the scope analysis diagrams between ADP and DDP of patent professionals (PP) is shown in Figure 7. It can be found in Figure 7 that after replacing ADP by DDP, the overall patent scope was apparently enlarged. While the scope of ADP was limited to the dotted straight lines, the scope of DDP expanded outwardly and significantly.

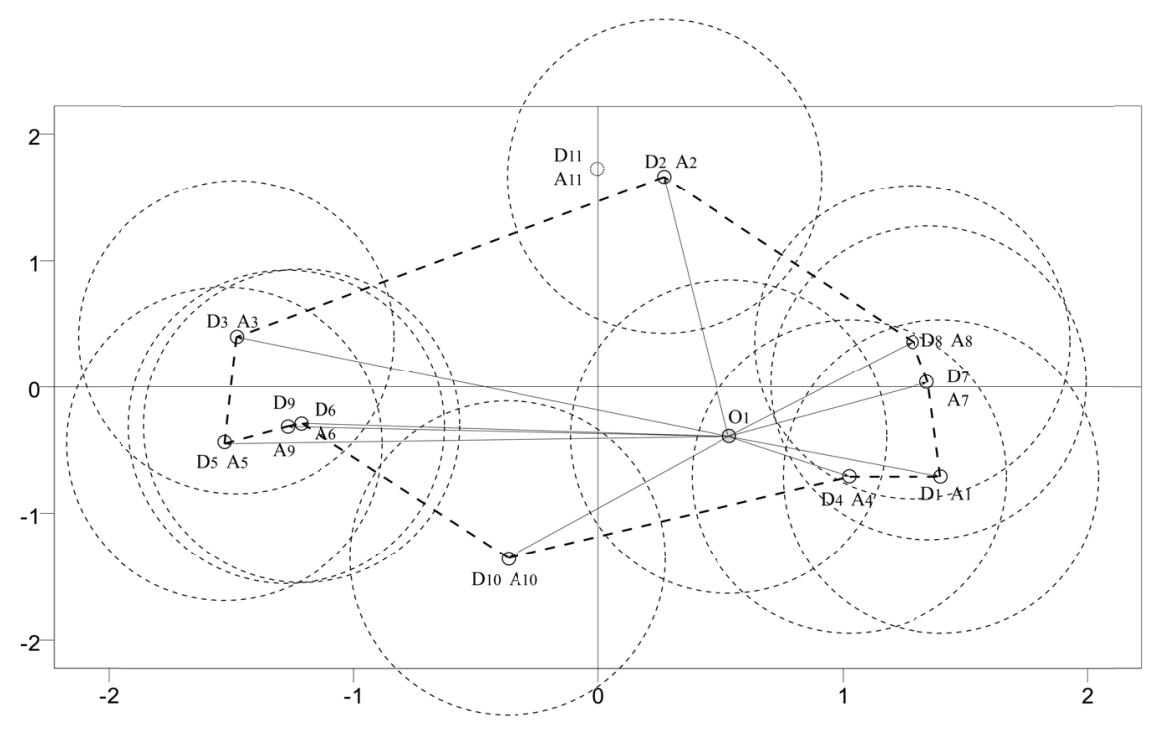

Figure 7. Comparison between ADP and DDP scopes constructed by patent professionals

(2) Design Professionals, DP

Comparison of the coverage of the scope analysis diagrams between ADP and DDP of design professionals (DP) is shown in Figure 8. It can be found in Figure 8 that after replacing ADP by DDP, the overall patent scope was apparently enlarged. While the scope of ADP was limited to the dotted straight lines, the scope of DDP expanded outwardly and significantly.

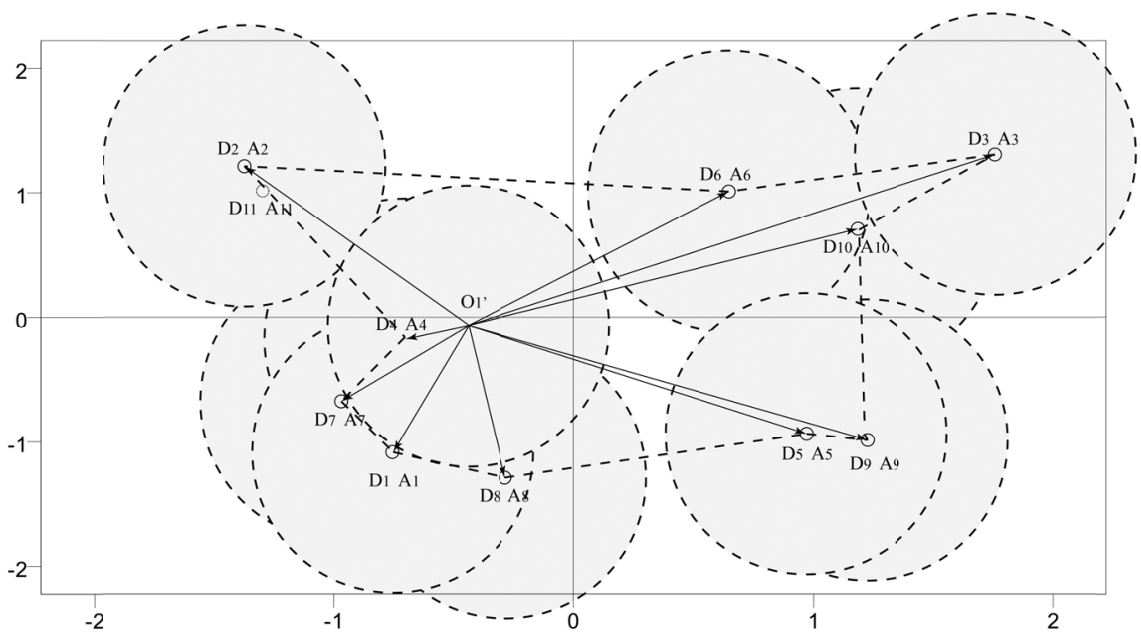

Figure 8. Comparison between ADP and DDP scopes constructed by design professionals 


\subsection{Judgmental Differences between PP and DP}

It can be found in Figure 9 for judgmental differences between PP and DP in the scope of ADP. The fine dotted lines denote PP while the thick dotted lines denote DP. When the two were superimposed, not much difference was found between PP and DP in terms of the scope of ADP. In other words, the actual areas constructed by DP and PP were very similar in size (i.e., similar ADP scope).

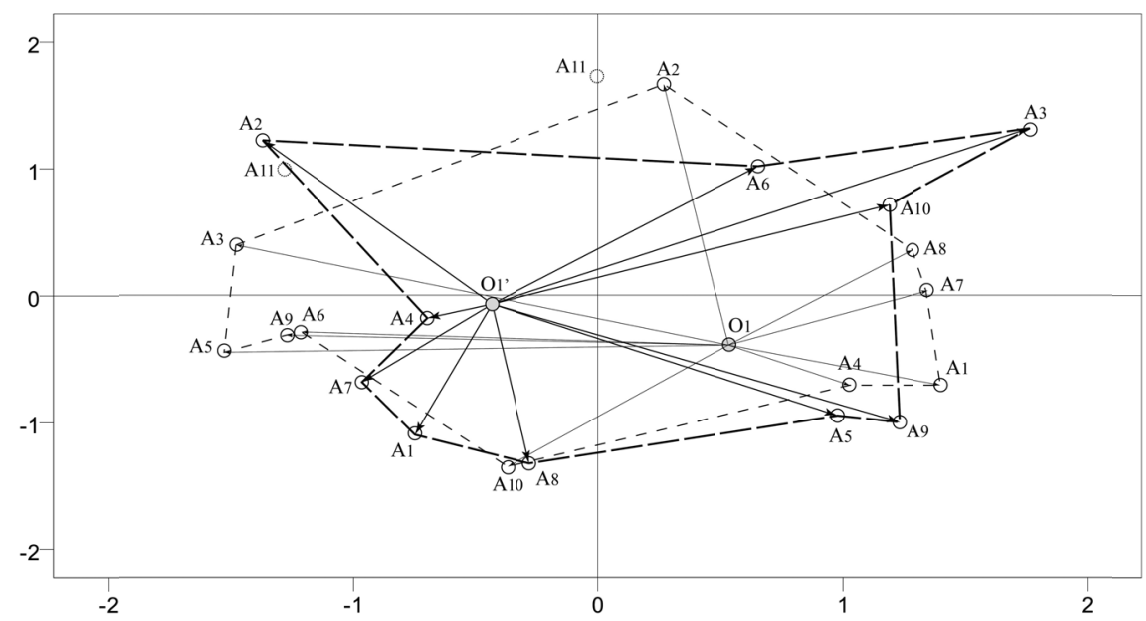

Figure 9. ADP judgmental differences between patent professionals and design professionals

It can be found in Figure 10 for judgmental differences between PP and DP in the scope of DDP. The fine dotted lines denote PP while the thick dotted lines denote DP. When the two were superimposed, not much difference was found between PP and DP in terms of the scope of DDP. In other words, the actual areas constructed by DP and PP were very similar in size (i.e., similar DDP scope).

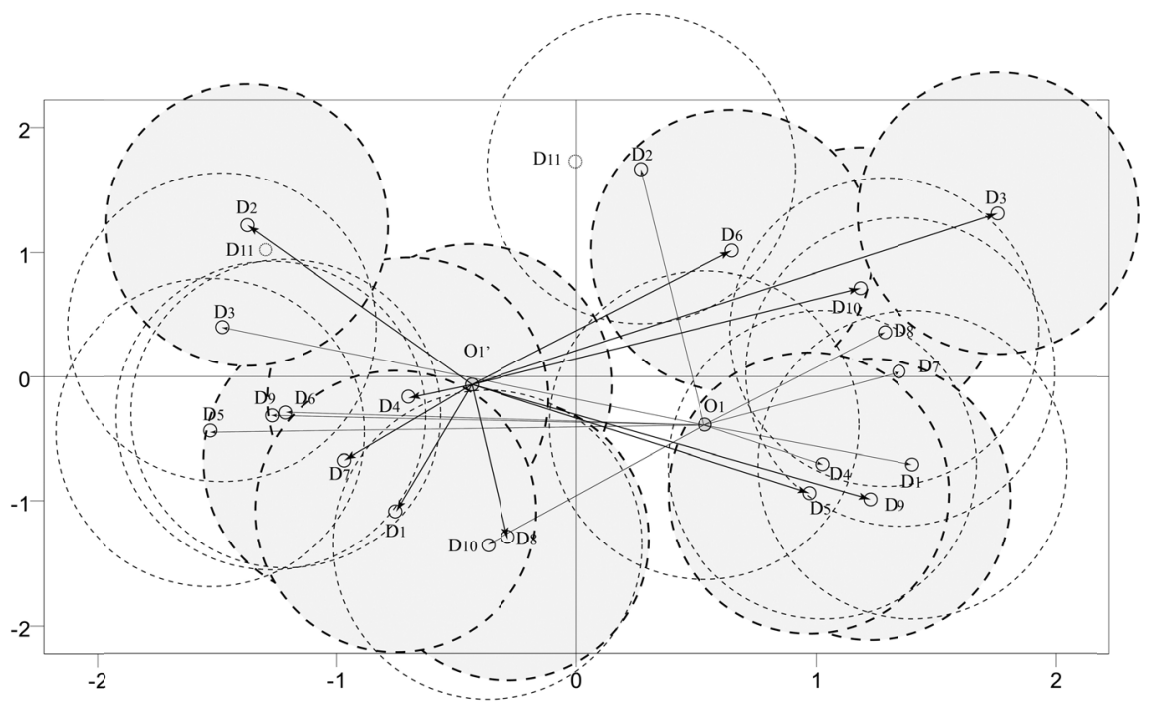

Figure 10. DDP judgmental differences between patent professionals and design professionals

\section{Discussion and Conclusion}

The main purpose of the study is to discuss the DDP system of design patent rights. Substantial differences exist between the new law (DDP) and the old one (ADP) in terms of their essence. Some examples are presented below. (1) DDP allows independent right claiming without being included under the original design patent. (2) DDP should be 
applied before the announcement of approval of the original design. (3) The patent right of DDP and the original design are to be expired concurrently. These three points make DDP different from the conventional ADP.

Some more important questions are presented below. First, has the scope of rights of design patents been affected by the implementation of the DDP system? According to results presented in Section 3.4, regardless of whether the scope of DDP patent rights was constructed by PP or DP, the scope was significantly enlarged, meaning that the DDP system provides designers with a broader patent right scope. Positively, it can spark companies to value the layouts of design patents. In general, the DDP system has created a more comprehensive design protection environment, which is definitely beneficial for Taiwan, which is moving into the creative industries.

Strictly speaking, there is little difference between the patent scope constructed by PP and by DP. It is possible that because both PP and DP are from professionals of this domain, the patent scopes constructed by them are very similar. This outcome can be applied to resolve the lack of patent personnel. Maybe the government of Taiwan can introduce DP into patent retrieval or patent review operation when appropriate. By doing so, delaying in patent review because of PP manpower shortage can be effectively resolved because the study has found that DP's design judgment is similar to PP's.

For patent strategies, the DDP system makes O1 patent rights more solid. Moreover, D1-D10 possesses independent design patent rights. Companies in the future can make a good use of the DDP system for patent layouts. By doing so, they can effectively safeguard the original patent design (O1) and protect their original design patent (O1) and DDP from any imitation or plagiarism. When DDPs (D1-D10) differ from each other significantly, the created patent scope can be maximized. The research conclusion here can be referred to by industries when planning their patent layouts.

The key contribution of the study lies in the application of actual design patent samples for constructing the scope of design patent rights, which was theoretical only in the past. By making the design patent into a two-dimensional patent sample, patent related personnel (such as judges and companies) can have a clear and concrete description of the patent scope. It is recommended that in design patent lawsuits, the plaintiff, the defendant, and even the judge should adopt the method proposed here to objectively evaluate and examine the scope of their design patents concretely.

\section{References}

Cao, Z., \& Zhao, H. (2008). Research of knowledge acquisition and modeling method based on patent map. 2008 IEEE International Symposium on Knowledge Acquisition and Modeling Workshop Proceedings, 1090-1094. http://dx.doi.org/10.1109/KAMW.2008.4810683

Chen, A., \& Chen, R. (2007). Design patent map: An innovative measure for corporative design strategies. Engineering Management Journal, 19(3), 14-29.

Chen, C. C., Chen, R., Wang, D.C., \& Dai, T.T. (2011). GA-based dissimilarity visualization engine for design patent map systems. Proceedings of the 2011 11th International Conference on Hybrid Intelligent Systems, 595-600. http://dx.doi.org/10.1109/HIS.2011.6122172

Chen, C.C., Chen, R., \& Dai, T.T. (2011). Framework of design patent map systems based on dissimilarity from populace survey. Communications in Computer and Information Science, 264, 75-82. http://dx.doi.org/10.1007/978-3-642-27210-3_9

Chen, R., \& Kuo, H. T. (2013). Similarity Scope of Design Patent Rights. Journal of Industrial and Production Engineering, 30(4), 211-219. http://dx.doi.org/10.1080/21681015.2013.816378

Davis, G. (1993). War of the Words: Intellectual Property Laws and Standardization. IEEE Micro, 13(6), 19-27. http://dx.doi.org/10.1109/40.248049

Hsu, Y. L., Hsu, P. E., \& Hung, Y. C. (2009). Development of a design methodology based on patent and axiomatic design. Journal of Quality, 16(3), 153-163.

Hwang, C. R. (2004). The study of Taiwan"s associated design patent. Thesis of Shih Hsin University.

Morris, J. L. (2012). Adding value to product designs: The convergence of designpatents and trade dress. Annual Technical Conference - ANTEC, Conference Proceedings, 3, 1741-1745.

Qiu, Q. Y., Zhang, H., \& Feng, P. E. (2011). Method to aid product innovation by patent knowledge. Journal of Zhejiang University, 45(2), 228-233.

TIPO. (2014). Substantive examination guidelines for patent, Taiwan Intellectual Property Office, TIPO. Retrieved 
June 30, 2014, from http://www.tipo.gov.tw/lp.asp?CtNode=6726\&CtUnit=3235\&BaseDSD=7\&mp=1

Yeh, H. M. (2005). Introduction of U.S. design patent. Intellectual Property Rights, 73, 31-68.

Yeh, H. M. (2009). Analysis of design patent protection on the same design concept (II)- Comparison similar design patent system of China, Taiwan, United States, Japan, and EU. Retrieved April 22, 2014, from http://www.naipo.com/Portals/1/web_tw/Knowledge_Center/Design_Patent/publish-12.htm

Yeh, H. M. (2010). The design patent visual observation and infringement judgment on the small items (II). Retrieved April 22, 2014, from http://www.naipo.com/Portals/1/web_tw/Knowledge_Center/Design_Patent/publish-19.htm

Zhang, J., Zhang, H., Sun, J., \& Tan, R. (2007). Technique of product technology evolutionary potential mapping based on patent analysis. 2007 IEEE International Conference on Industrial Engineering and Engineering Management, 2033-2037.

Bel, A. "Socket", Taiwan Patent No. 398790 (087305353), 2000/07/11.

Bel, A. "Socket", Taiwan Patent No. 414572 (087305353U01), 2000/12/01.

Bel, A. “Socket”, Taiwan Patent No. 414573 (087305353U02), 2000/12/01.

Bel, A. "Socket”, Taiwan Patent No. 414574 (087305353U03), 2000/12/01.

Bel, A. "Socket", Taiwan Patent No. 414575 (087305353U04), 2000/12/01.

Bel, A. "Socket", Taiwan Patent No. 414576 (087305353U05), 2000/12/01.

Bel, A. "Socket", Taiwan Patent No. 414577 (087305353U06), 2000/12/01.

Bel, A. "Socket", Taiwan Patent No. 414578 (087305353U07), 2000/12/01.

Bel, A. "Socket”, Taiwan Patent No. 414579 (087305353U08), 2000/12/01.

Bel, A. "Socket", Taiwan Patent No. 414580 (087305353U09), 2000/12/01.

Bel, A. "Socket”, Taiwan Patent No. 414572 (087305353U10), 2000/12/01. 